\title{
Review of Well Logs and Petrophysical Approaches for Shale Gas in Sichuan Basin, China
}

\author{
Yuanzhong Zhang*, Sicheng Jin, Hao Jiang, Yuwei Wang and Pengyu Jia
}

State Key Laboratory of Petroleum Resources and Prospecting, College of Geophysics and Information Engineering, China University of Petroleum, Beijing 102249, China

\begin{abstract}
China has vast reserves of shale gas. Currently, shale gas is one of the focuses of the unconventional reservoir. Well logs play an import role in shale gas production, and it is the bridge connecting geology, geophysics and petroleum engineering. In the exploration stage, well logs are used to identify lithology, evaluate the parameters of mineral types and compositions, total organic carbon (TOC), porosity, permeability, gas content, and the potential resources quantity. In the development stage, well logs offer various parameters of geological and engineering for horizontal drilling and production, evaluate the mechanical properties and calculate the magnitude and orientation of the in-situ stress for hydraulic fracturing stimulation. We reviewed current well logs for shale gas in China and discussed the development trend in the paper. A case history in Sichuan Basin presented to analyze the logs response characteristics and parameters calculation for a shale gas well. The difficulty and the future attention focus are also discussed.
\end{abstract}

Keywords: China, shale gas, Sichuan Basin, unconventional reservoir, well logs.

\section{INTRODUCTION}

Shale is widespread, collectively termed a whole family of marine or lake sedimentary rock from claystone to slate, which is made of clay minerals, non-clay minerals of the organic-rich dark-colored mud shale and high carbon shale, fine particle silt mudstone, muddy siltstone and silt sandstone. The trapped gas in shale, clay and the fine-grained sedimentary rocks is often termed shale gas [1-2]. Shale gas is mainly stored in the shale formation with two states of the absorbed gas and the free gas. The absorbed gas is trapped in the organic matter and the interface of the minerals solid particle; and the free gas stores in the natural fracture and the relative large-size pore [3-8].

Shale, which is made up of the fine grained particles with the large specific surface area, could store a large amount of gas. The potential reserve of shale gas around the world is huge, mainly distributed in North America, Latin America, Middle East, North Africa, Central Asia, Russia and China [1]. Up to now North America has realized the commercial development. With the growing shortage of the conventional oil and gas resources, the unconventional shale gas is increasingly receiving much recognition worldwide. The shale gas reserve in China would be the second largest in the world. Hydrocarbon resources shortage forces Chinese government to accelerate its steps on the shale gas exploration and development as well.

Shale is often seen as the barrier layer (cap rock or interlayer) of the oil and gas reservoir, and it is also routinely ignored in formation evaluation. Study on shale is valued

*Address correspondence to this author at the State Key Laboratory of Petroleum Resources and Prospecting, College of Geophysics and Information Engineering, China University of Petroleum, Beijing 102249, China;

Tel: 86-10-89731962; Fax: 86-10-89731962; E-mail: zhangyz@cup.edu.cn until shale gas is regarded as a kind of the unconventional gas resources to develop. Gas-bearing shale with fracture has characteristics of low porosity and low permeability, and the logs response is also complicated. Investigation of the rock physics and the logs response would be one of the key problems to be solved for shale gas development [1,5-8].

The technical means for shale gas has something in common with oil and gas resources exploration and development. Well logs are one of the essential methods for shale gas, and the well logs method and the tools are almost the same as the conventional oil and gas resources. Some basic problems including the types of rock and mineral, fluid identification and evaluation and rock mechanics parameters calculation for shale gas make the well logging suite the same as the conventional oil and gas reservoir. The conventional well logging suite, including nine curves, namely, Spontaneous Potential (SP) log, Gamma Ray (GR) log, Caliper $\log$, Acoustic log (AC), Density log, Neutron log, Deep Laterolog Resistivity log and Shallow Laterolog Resistivity $\log$ (RLLD, RLLS), Micro Sphere Focused Log (MSFL), play a primary role in shale identification, the effective formation thickness and various parameters calculation. Some special well logging suites, such as elemental and mineralogy well logs (i.e., Elemental Capture Spectroscopy, ECS), Nuclear Magnetic Resonance (NMR) logging, Cross-dipole acoustic log, Imaging Logs and LWD/MWD, solve the problems of the shale minerals composition calculation and the fracture identification [9-14].

The shale gas well logs in China started late, but developed rapidly. In this paper, we review the status of shale gas well logs in China. The key well logging suites and its application was introduced. The well logs response with the conventional well logging was summarized to quickly identify the gas-bearing shale reservoir, the formation evaluation 
methods and some petrophysicsal parameters are also analyzed. A case history of shale gas logs in Sichuan Basin in the Southwest China, which it is a current hotspot of shale gas exploration and development, is introduced. The difficulties and the future research focus are also discussed.

\section{KEY WELL LOGS SUITES}

Now the shale gas well logs are nearly the same as the conventional oil and gas, including the conventional well logging suite and the special well logging suite. The conventional well logging suite satisfies the need of the lithology identification and formation parameters calculation [10-14]. GR often helps to distinguish the gas-bearing shale from shale. SP is used to classify the effectiveness of the shale gas reservoir. RLLD and RLLS reflect gas-bearing properties of shale. Density qualitatively analyzes lithology. The special well logging suite often plays important role in the evaluation of the element type and the content, clay minerals type and content, fracture identification, etc.

The shale gas productive capacity mainly depends on several factors of the intrinsic fractures, brittleness, drilling and completion [15-30]. The porosity and matrix permeability of shale are all very low. How to improve the shale permeability must be considered. The horizontal well and the volume fracturing are the two key technologies for the shale gas production. Well logs are necessary to guide drilling deployment and optimize shale reservoir reform as a technical support run through the shale gas development, especially LWD/MWD [23, 30]. Some key technologies of the formation evaluation are as follows:

1) Choosing the best drilling target and guiding the drilling direction with LWD/MWD.

2) Combination wireline logs and LWD/MWD to analyze how to obtain the most effective multi-layer fracture in reservoir reform.

3) Guiding drilling trajectory to avoid the large fault, troublesome region and aquifer with LWD/MWD.

4) Preventing the height of the fracture in the fracturing stimulation from communicating the potential karst with LWD/MWD.

5) Fracturing stimulation monitoring with downhole wireline microseismic.

6) Integrating wireline $\operatorname{logs}$ with core analysis to evaluate the hydrocarbon generation capacity, the storage capacity and the productive capacity.

Currently the formation evaluation of shale gas mainly focus on the following some aspects.

1) Shale gas reservoir identification and the potential hydrocarbon generation evaluation, including a series of qualitative or quantitative interpretation indexes, such as shale gas reservoir classification, kerogen recognition and kerogen type classification, TOC, organic matter content, thermal maturity.

2) Lithology and reservoir parameters evaluation, including shale lithology identification (minerals type, composition and content), porosity, gas content, permeability, etc.
3) Rock mechanics parameters calculation, anisotropy and in-situ stress evaluation for gas-bearing shale.

4) Fracture identification.

5) Real-time monitoring fracturing azimuth and fracturing effect.

6) Real-time monitoring horizontal well drilling and production process.

The target of the well logs evaluation for gas-bearing shale is to form the well logging evaluation supporting technology series with hydrocarbon generation capacity, storage capacity and production capacity. The well logging suite and the petrophysical parameters available for shale gas are shown as Table 1. The technical requirements in well logs for shale gas mainly involved some aspects as follows:

1) Shale petrophysical parameters calculation model.

2) Well logs response characteristics identification and evaluation method for the sensitive geophysical parameters.

3) Evaluation method and calculation model for TOC and thermal maturity.

4) Shale reservoir effectiveness evaluation.

5) Calculation model and evaluation method for the free gas content, absorbed gas content, gas saturation and the total volume of gas.

6) Calculation model for shale, sand content, clay minerals composition and brittle minerals content (sand, calcite and feldspar, etc).

7) Rock mechanics parameters calculation method.

8) Quantitative fracture identification and in-situ stress evaluation.

\section{WELL LOGS RESPONSE}

Although the well logs response of the gas-bearing shale is complicated, shale gas reservoir has obviously characteristics in the conventional well logging curves [31-37]. Concretely, both GR and resistivity are all high. Caliper usually expands. RLLD and RLLS show medium or low value and negative separation in the shale reservoir. Three porosity curves, Density, Neutron and AC, indicate high value, and $\mathrm{PE}$ is low, shown as Table 2. Moreover, the gas-bearing shale also has the characteristics of low density, low hydrogen index and low sonic velocity. The organic matter content and the uranium content are all high. The density of the kerogen is low, and the density of the shale often ranges from $2.45 \mathrm{~g} / \mathrm{cm}^{3}$ to $2.75 \mathrm{~g} / \mathrm{cm}^{3}$. The gas bearing shale can be easily and quickly identified with the log curves $[4,10]$.

The well logs response analysis for shale gas reservoir include lithology, physical property, electrical property, gasbearing properties, source rock, in-situ stress and anisotropy, also termed seven-property relationship analysis [11, 13]. Fig. (1) is the conventional well logs response of a shale gas well in Sichuan Basin. The shale gas formation locates in the bottom of the Longmaxi Formation, and the thickness is nearly $90 \mathrm{~m}$. The gas logging has good indication. The lithology is argillaceous shale and carbonaceous shale with 
Table 1. Logging suite and parameters available for shale gas.

\begin{tabular}{|c|c|c|}
\hline No. & Logging Suite & Parameters Available \\
\hline \hline 1 & Resistivity, Density and Neutron combination logs & 1) porosity, permeability, saturation \\
\hline 2 & Natural Gamma-ray Spectral Log & 3) minerals composition, siliceous index, brittleness \\
\hline 3 & Elemental Capture Spectroscopy (ECS) lithofacies \\
\hline 4 & NMR & 4) TOC \\
\hline 5 & Micro Resistivity Imaging, Circumferential Acoustic Scanning Imaging log & 5) thermal maturity \\
\hline 6 & Cross-dipole acoustic log & 6) gas content \\
\hline 7 & Sidewall Coring and Core analysis & 7) fracture and its occurrence \\
\hline 8 & LWD/MWD & 8) dynamic and static rock mechanics parameters \\
\hline 9 & Microseismic monitoring for hydraulic fracturing stimulation & 9) pressure gradient
\end{tabular}

Table 2. The response characteristics of well logs curves.

\begin{tabular}{|c|c|c|c|}
\hline Well Logs Curves & Parameters & Curves Characteristics & Influence Factor \\
\hline GR & Natural radioactivity & $\begin{array}{l}\text { High (>100API), local } \\
\text { low value }\end{array}$ & $\begin{array}{l}\text { GR is high with shale increasing. The organic matter has high radioac- } \\
\text { tive material, GR is more than } 100 \mathrm{API} \text {, some exceeds } 400 \mathrm{API}\end{array}$ \\
\hline Caliper & Borehole diameter & $\begin{array}{l}\text { Borehole diameter } \\
\text { expanding }\end{array}$ & $\begin{array}{c}\text { The diameter of shale is expanding, and it is more serious with organic } \\
\text { matter existing }\end{array}$ \\
\hline $\mathrm{AC}$ & slowness & High and cycle skip & $\begin{array}{l}\text { Slowness is large with high organic matter abundance or high gas con- } \\
\text { tent. The cycle skip is induced by crack or fracture }\end{array}$ \\
\hline Neutron & porosity & high & $\begin{array}{l}\text { The clay bound water leads to high neutron porosity. But neutron poros- } \\
\text { ity decreases with gas content increasing }\end{array}$ \\
\hline Density & density & low & $\begin{array}{c}\text { The high gas content, organic matter abundance, high fracture density } \\
\text { and diameter expansion }\end{array}$ \\
\hline Lithology density & $\mathrm{PE}$ & low & Hydrocarbon, gas content, fracture \\
\hline Resistivity & RLLD, RLLS & $\begin{array}{l}\text { high, local low value, } \\
\text { and RLLD is nearly } \\
\text { overlaps RLLS }\end{array}$ & $\begin{array}{l}\text { Permeability, shale content and bound water induces low resistivity. The } \\
\text { resistivity of the kerogen is higher, the response is also high }\end{array}$ \\
\hline
\end{tabular}

inclusions of the grey and siltstone. The Caliper is normal without washout. GR in the shale gas layer is high, and the average is larger 160API. High TOC in the bottom is corresponding for high gas content, where the average of GR is larger than 180API. AC slowness in shale gas reservoir usually increases. The slowness of Longmaxi Formation moderately increases, where the average of sandstone is $72 \mathrm{us} / \mathrm{ft}$. and the shale is $78 \mathrm{us} / \mathrm{ft}$.

The density of the organic matter is often low, and density of the matrix is relative high. The density is gradually reduces from $2.75 \mathrm{~g} / \mathrm{cm}^{3}$ to $2.45 \mathrm{~g} / \mathrm{cm}^{3}$ with TOC and gas content increasing. The highest TOC and gas content corresponds to the lowest density. The neutron porosity reduces to $12 \%$ with obvious excavation effect, but the porosity of the surrounding rock is about $21 \%$. The resistivity slowly changes, and the average is about $42 \Omega . \mathrm{m}$. The content of the uranium element is high and the thorium is low. The difference of GR and natural GR spectrum (NGS) without uranium become large with TOC and gas content increasing.

\section{SHALE GAS RESERVOIR IDENTIFICATION METHODS IN FORMATION EVALUATION}

The lithology identification is primary in the shale gas formation evaluation, then the petrophyscial parameters calculation and the productivity evaluation. Several methods have been developed to identify gas-bearing shale, namely the conventional well logs combination, the well logging cross-plot, the gas logging, $\Delta \log \mathrm{R}$ method, the dielectric constant method and the combination parameters method [4, 30]. The log methods applied in shale reservoir identification have been gotten good results. 


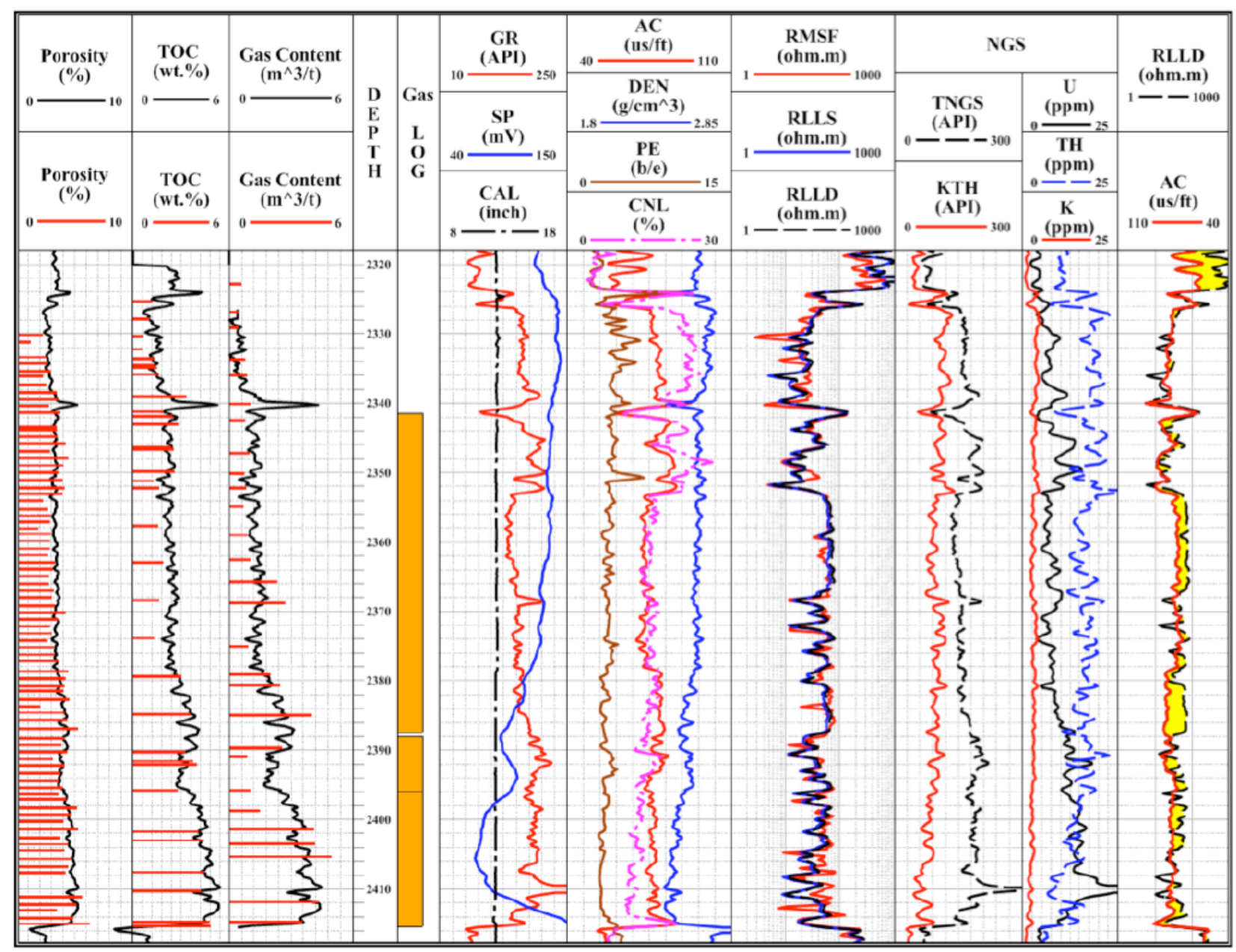

Fig. (1). A logs interpretation plot of shale gas well in Sichuan Basin. The three tracks on the left are porosity, TOC and gas content respectively, where the black solid line is the calculation with logs data and the red bar is the core analysis data. The forth track is depth, and the fifth track is gas logging. The sixth track, the seventh track and the eighth track are the conventional logs, including CAL, SP, GR, AC, DEN, PE, CNL, RLLD, RLLS and MSFL. The ninth track is natural GR spectrum (NGS). U, TH and K are the content of uranium, thorium and potassium respectively. TNGS is total NGS and KTH is NGS without U. The tenth track is the overlaps graph of AC and RLLD. The unit of each curve is in the bracket.

\subsection{The Conventional Well Logs Combination}

The conventional well logs combination, such as GR, Density, AC, Neutron and Resistivity, effectively identify the shale gas reservoir and lithology according to the typical well $\log$ s response [4-5].

\subsection{The Well Logs Cross-plot}

The well logs cross-plot with AC slowness and Resistivity is used to determine the shale boundary to identify lithology, furthermore distinguish the gas-bearing shale zone with organic-rich matter.

\subsection{Gas Logging}

The gas logging indications have close corresponding relation with lithology in the process of drilling. The cap rock of the shale layers, with low permeability and high hydrocarbon content, such as calcilutite, dolomite, salt rock, easily occur kick and leakage. It also shows the growing fractures and high gas content. The shale gas reservoir is well identified accordingly. The gas logging method has been used to identify shale gas reservoir in the Longmaxi Formation in
Sichuan Basin, and find out the direct evidence of the growing shale, shown as Fig. (1). The gas logging indication is abnormal and active, kick and leakage occasionally occur, shows the presence of shale gas and widespread.

\subsection{Radioactivity Logs Combination with the Conven- tional Well Logs}

The fine grained clastic rock with high abundance of organic matter is usually accompanied with the trend of high concentration of the radioactive elements, low bulk density, low sonic velocity and high resistivity [4,38-39]. The combination of the radioactivity logs and the conventional logs easily identify the shale gas reservoir.

\section{5. $\Delta \log R$ Method}

$\Delta \log \mathrm{R}$ method is often used to evaluate the hydrocarbon content of the source rock with the well logs [38-39]. The scaled porosity logs curve (slowness) superimposes on the resistivity curve (RLLD). As the two curves all corresponds to the difference of the porosity, the basic coincidence together reflects the formation saturated with water but lack of 
organic matter. The amplitude separation of $\Delta \log \mathrm{R}$ indicates the source rock with abundant organic matter, the reservoir containing hydrocarbon and lithology difference.

The shale formation without hydrocarbon can easily be identified and eliminated with GR, compensated neutron porosity and SP. The separation of the two curves in the shale reservoir with abundant organic matter often induces two factors. The separation of the porosity curves is the response of the kerogen with low density and low sonic velocity (high slowness). There is no hydrocarbon generation in the immature and abundant organic matter formation, and the observed difference of the two curves is only the response of the porosity difference. In the mature hydrocarbon source rock, the difference becomes bigger with resistivity increasing.

\subsection{The Dielectric Constant}

Both the experiments and the well logs data have proved that the shale containing hydrocarbon has high dielectric constant value, but the shale without hydrocarbon has low value. The response of the dielectric log would be taken as a sign for shale gas reservoir [41-44].

\section{THE KEY PETROPHYSICAL PARAMETERS}

The exploration and development of shale gas need with help of well logs and core analysis to know about the petrophysics and evaluate the amount of the organic matter and types, trace elements, maturity, types of kerogen, hydrogen content, petrophysical parameters, rock mechanics parameters, in-situ stress and anisotropy, etc.

The key petrophysical parameters in formation evaluation include shale minerals composition, thickness, types and content of kerogen, TOC, maturity, dry absorbed gas (gas saturation), free gas content in pore and fracture, porosity, permeability, etc.

\subsection{The Shale Minerals Composition}

The gas bearing shale is composed of shale, clay and silt sandstone, which the grain range of the particle size changes from clay (<5um) and silt (5-63um) to sand (>63um) [4, 6, 39].

Generally the shale has high content of quartz to increase the brittleness. Moreover the shale also contains some metal minerals. The minerals content, clay and the quartz, influence the engineering and well logs.

The minerals composition of shale would be measured by $\mathrm{X}$-ray diffraction and X-ray energy spectrum in the laboratory. ECS and radioactivity logs directly provide the minerals and oxide content. The cross-plot with the various conventional well $\operatorname{logs}$ also can be used to identify the minerals composition of the shale.

\subsection{Thickness}

The shale gas productive capacity depends on two key technologies, horizontal well and hydraulic fracturing stimulation. The thickness of gas-bearing shale would be significant, if the thickness is small, the operation of the horizontal well and fracturing stimulation would be lost the commercial feasibility. The vertical thickness of the organic matter abundant is most important for fracturing stimulation. In general speaking, the profitable target would be the vertical thickness of $45 \mathrm{~m}$ with high TOC. The average thickness of the source in the Lower Cambrian in South China is about $139 \mathrm{~m}$, and the Lower Silurian is about $100-700 \mathrm{~m}$. The shale thickness of Jiyang Depression in North China to Northeast China is more than $100 \mathrm{~m}$, and Yanchang Formation in Upper Trissic in Ordos Basin is about 300-600m [13]. They are the potential shale gas development areas. The thickness of the shale gas reservoir can be determined with the conventional well logs and sometimes combined with mud logging, gas logging and core analysis data.

\subsection{TOC}

TOC is an important parameter for shale gas. TOC is close related with kerogen content and types. The organic matter content is the main influence factors of the hydrocarbon-generating intensity and the quantity of hydrocarbon generation. TOC also can be used to evaluate the hydrocarbon generation capacity. The experiment results have shown that the absorption capability of the shale is linearly correlated with TOC and gas content.

Several methods are used to estimate TOC with well logs $[4,33,36,38-40] . \Delta \log \mathrm{R}$ method not only identifies shale gas reservoir but also calculates TOC [38-39]. The relationship between $\triangle \log R$ and TOC is given by

$$
\begin{aligned}
& \Delta \log \mathrm{R}=\lg \left(\frac{\mathrm{R}}{\mathrm{R}_{\text {baseline }}}\right)+\mathrm{K} \times\left(\Delta \mathrm{t}-\Delta \mathrm{t}_{\text {baseline }}\right) \\
& \mathrm{TOC}=(\Delta \log \mathrm{R}) \times 10^{2.297-0.1688 . \mathrm{LOM}}
\end{aligned}
$$

Where $\Delta \log \mathrm{R}$ is the separation between the scaled porosity curve and resistivity curve. $\mathrm{R}$ is the logging reading of resistivity, and $R_{\text {baseline }}$ is resistivity baseline of the nonhydrocarbon source. $\Delta t$ is the logging slowness reading of $\mathrm{AC}$, and $\Delta \mathrm{t}_{\text {baseline }}$ is the slowness baseline of the nonhydrocarbon source. $\mathrm{K}$ is scale factor, and for units of $\mu$ sect $/ \mathrm{ft}$ and $\mu \mathrm{sec} / \mathrm{m}$, it is 0.02 and 0.065 , respectively. LOM is thermal maturity, which has relation with vitrinite reflectance (R0), commonly provided by the laboratory.

Actually $\Delta \log \mathrm{R}$ appears in source rock, oil-prone formation and evaporate [38]. In the logs data continuous processing of TOC profile, other lithology interference should be discharged with GR and Caliper to find out the mature source. Higher GR based on the generation of kerogen is in the reducing environment with relatively high uranium (U) content. The main elements content obtained by ECS could approximately get TOC.

TOC also has empirical linear relation with density log using regression method with core analysis data, which is given by

TOC $=-15.47 \rho+42.98$

Where $\rho$ is density logging reading. The density is negative correlation with TOC. The density and TOC from core analysis data show the good relevance, shown as Fig. (2).

There is a good linear relationship between TOC and shale gas production rate. The exploration target in North America mostly chooses TOC larger than $2 \mathrm{wt} \%$, even over 4 wt\%. In Lower Cambrian of Sichuan Basin, TOC of Qiongzhusi Formation is $1 \mathrm{wt} \%-11 \mathrm{wt} \%$ and generally larger than $1 \mathrm{wt} \%$, Longmaxi Formation is in the range of $0.5 \mathrm{wt} \%$ - 
$5 \mathrm{wt} \%$, even up to $9 \mathrm{wt} \%$ with high gas content. TOC in gas shale is $1 \mathrm{wt} \%-20 \mathrm{wt} \%$ [13]. Higher TOC frequently means higher gas production capacity.

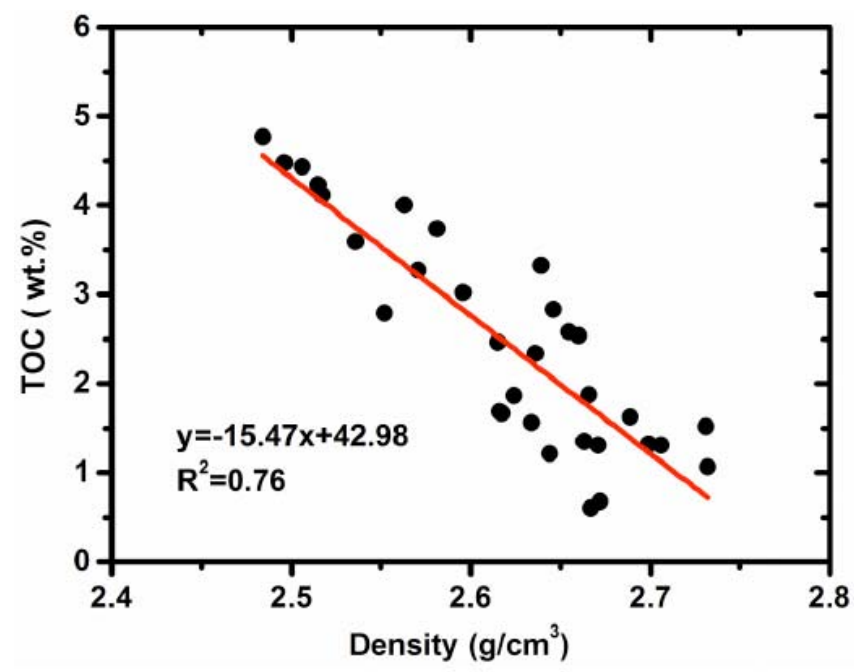

Fig. (2). The cross-plot of density and TOC. The $x$-axis is density, and the $y$-axis is TOC. The circle black dot is the core analysis data, and the red line is the fitting. The formula is linear fit.

The separation between porosity and resistivity has weak correlation with TOC, and the separation doesn't rise with TOC increasing, shown as Fig. (1). TOC is calculated with Density, where the density of organic matter is low and close to $1.0 \mathrm{~g} / \mathrm{cm}^{3}$ and the density of the matrix clay is $2.7 \mathrm{~g} / \mathrm{cm}^{3}$.

\subsection{Maturity}

The maturity is an essential index to evaluate the source. There are several indexes referred to maturity, vitrine reflectance R0, thermal alteration index (TAI), RockEval pyrolysis temperature (Tmax) and conodont alteration index (CAI), and these parameters usually are related with R0. At present the logs data is available for the maturity index (MI) evaluation with resistivity and the combination methods of neutron $\log$ and density $\log [25,40]$. The formula of MI is given by [25].

$\mathrm{MI}=\sum_{\mathrm{i}=1}^{\mathrm{N}} \frac{\mathrm{N}}{\phi_{\mathrm{n} 9 \mathrm{i}}\left(1-\mathrm{S}_{\mathrm{w} 75 \mathrm{i}}\right)^{1 / 2}}$

Where $\mathrm{N}$ is the sample numbers which density porosity is greater than or equal to $9 \%$ and water saturation less than or equal to $75 \%$ at sampling depth. $\phi_{\mathrm{n} 9 \mathrm{i}}$ is neutron porosity where density porosity is greater than or equal to $9 \%$ at each sampling depth. $\mathrm{S}_{\mathrm{w} 75 \mathrm{i}}$ is water saturation where density porosity is greater than or equal to $9 \%$ and saturation less than $75 \%$ at each depth.

$S_{w i}=\left(\frac{R_{w}}{\phi_{d 9 i}^{m} R_{t}}\right)^{1 / 2}$
$\phi_{d 9 i}=\phi_{d}-0.09$

Where $S_{w i}$ is water saturation. $R_{w}$ is water resistivity. $m$ is cementation index. $\phi_{\mathrm{d}}$ is matrix porosity estimated by density logging data. $R_{t}$ is resistivity. $M I$ is average value integrated the core analysis data and the logs reading in effective gas shale layers which density porosity is greater than
9\% and hydrocarbon saturation greater than the minimum $25 \%$. MI is an inverse correlation with neutron porosity.

\subsection{Porosity}

Porosity estimation is mainly calculated based on the three porosity logs data, and core analysis data is often used to correct the results. Density porosity has relative high precision. The volume physical model is modified with TOC considering. It is given by [10]

$\rho_{b}=\rho_{m a} *\left(1-\phi-V_{T O C}\right)+\rho_{f} * \phi+\rho_{T O C} * V_{T O C}$

$\phi=\frac{\rho_{m a}-\rho_{b}+\mathrm{V}_{T O C} *\left(\rho_{T O C}-\rho_{m a}\right)}{\rho_{m a}-\rho_{f}}$

Where $\rho_{b}$ is density log reading. $\rho_{m a}$ is density of the matrix. $\rho_{f}$ is the density of the pore fluid. $\rho_{T O C}$ is the density of the organic matter. $\Phi$ is porosity. $V_{T O C}$ is the content of the organic matter. It is difficult to get high-precision porosity of shale because of the complicate lithology and logging response.

Porosity in the core interval is calculated with model built by core calibration logs. Density is used to obtain porosity without core analysis porosity, and the density of matrix and TOC are from ECS. Otherwise porosity is estimated by density log with the fitting relationship, shown as Fig. (3). And core analysis porosity has a good correlation with density in the shale gas reservoir.

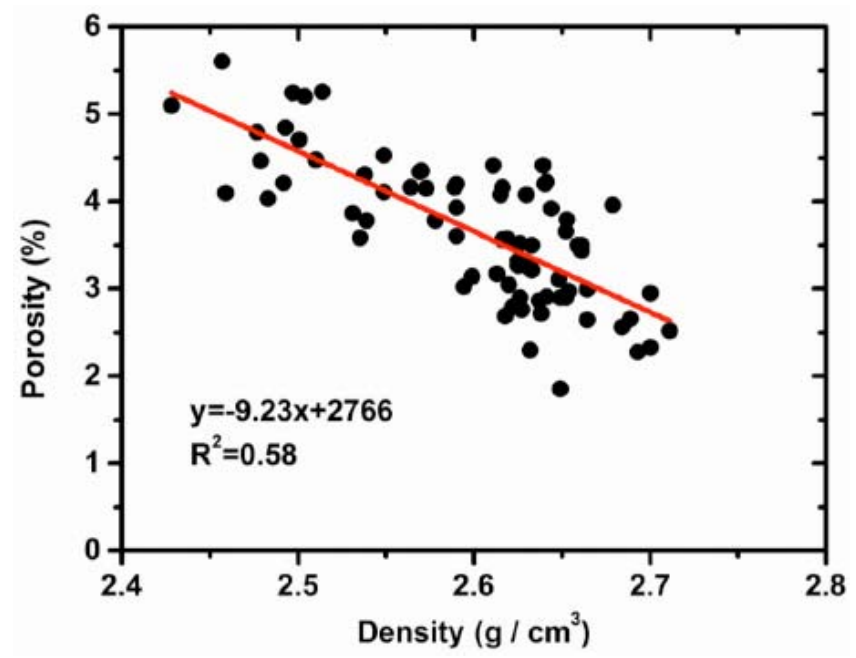

Fig. (3). The cross-plot of density and porosity. The $\mathrm{x}$-axis is density, and the $y$-axis is porosity. The circle black dot is the core analysis data, and the red line is the fitting. The formula is linear fit.

\subsection{Gas Saturation}

High gas shale content corresponds to large resistivity reading, which it is in accord with the conventional reservoir. Archie formula is often used to estimate the gas saturation. The gas content and TOC obtained by core analysis data also show good dependent, shown as Fig. (4), then the gas content would be calculate with TOC. In Fig. (1) porosity, TOC and gas content calculate with the logs data based on the fitting relationship is good consistent with core analysis data. 


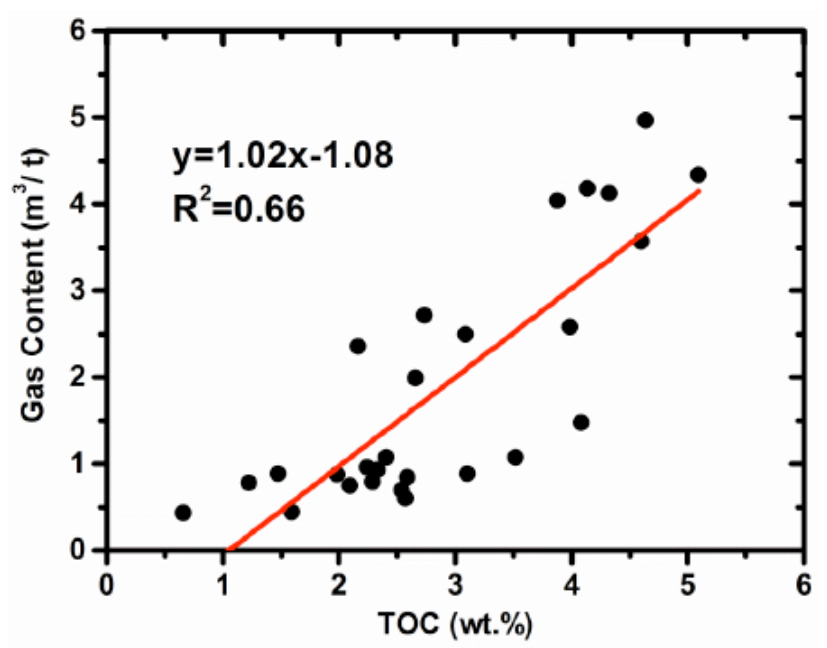

Fig. (4). The cross-plot of TOC and gas content. The $\mathrm{x}$-axis is TOC, and the $y$-axis is gas content. The circle black dot is the core analysis data, and the red line is the fitting. The formula is linear fit.

\subsection{Permeability}

The permeability of shale is very low, mostly in the range of $0.001-0.11 \times 10^{-3} \mu \mathrm{m}^{2}$. But shale also has high porosity and permeability with fractures. The measurement in the laboratory with GRI method show that the matrix permeability generally less than $0.1 \times 10^{-3} \mu \mathrm{m}^{2}$, and the average throat radius is also less than 0.005 um $[13,45-47]$. The average matrix porosity of Qiongzhusi Formation and Longmaxi Formation is about $1.6 \%$, the range of the matrix permeability is $(0.001-0.11) \times 10^{-3} \mu \mathrm{m}^{2}$ and the average is $0.019 \times 10^{-3} \mu \mathrm{m}^{2}$ [13]. But fractures and cracks often increase porosity and permeability of shale.

Currently permeability evaluation with well logs is still the same as sandstone with core calibration logs. The relationship between the permeability and the porosity is built with core analysis data, and permeability is calculated with porosity.

Otherwise some imaging analysis methods are often used to obtain porosity and permeability of shale in the laboratory. But it is dependent of image resolution and imaging processing method, and has large uncertainty [47-50].

\subsection{Rock Mechanics Parameters}

Rock mechanics parameters, such as elastic modulus, poisson ratio, shear modulus and bulk modulus, are very important for engineering operation in shale gas production. The shale gas reservoir has obvious anisotropy. Understanding of the orientation and the magnitude of the in-situ stress would help engineering design and operation [51-60]. Crossdipole acoustic log provides the slowness of compressional wave and shear wave to calculate the rock mechanics parameters based on the assumption of ideal elasticity, homogeneous and isotropy. The in-situ stress evaluation with well logs is combined with pore pressure analysis, image logs and core analysis. The in-situ stress test in fracturing is used to correct the calculation results.

\section{THE DIFFICULTY OF THE FORMATION EVAL- UATION}

Some differences between the shale gas and the conventional gas define the differences of the well $\operatorname{logs}$, which is the difficulty of the well logs evaluation lies.

1) The shale reservoir has the characteristics of low porosity, low permeability, self-source. The logs response of low porosity and low permeability is complicated and not obvious, which is also one of the difficulties of current formation evaluation.

2) The gas is mainly absorbed in the shale. The logs response of the absorbed gas is complicated and less understanding. The responses of the shale reservoir need to be furthermore investigated.

3) The lithology of shale reservoir is complicated and different from the conventional oil and gas reservoir. The silicon content of the known commercial developing shale gas reservoirs is larger than $28 \%$, and the microfracture is developed. The well logs interpretation model is quite different from the conventional.

4) The well logs theory and models based on assumption of the linearity, homogeneity, isotropy, ideal elasticity is not completely suitable for shale gas reservoir.

5) As shale is both self-source and reservoir, the trapped gas includes absorbed gas and free gas, and how to identify the state and content of the absorbed gas is another problem. The study of well logs interpretation for shale gas is insufficient.

In the recent years resource survey of shale gas in China has been carried out. The works indicate that the shale gas resources are very rich, largely distributed in the South China, North China, North-East China, South-West China and North-West China. The shale gas development is in its beginning stage compared with the abroad. The well logs evaluation faces some difficulties as following:

1) The depositional environment of shale reservoir is complex. The shale in China mainly formed in the marine facies and the littoral facies with high clay content, and the thickness, maturity and TOC, are all poor than those who have successfully development in North America. We should set up the well log methods and the formation evaluation methods to adapt to the shale gas reservoir without blindly copying the abroad experience.

2) The burial depth of shale gas is deep. The depth of the shale gas in Sichuan Basin is in the range of 2000$35000 \mathrm{~m}$, and the difficulty in developing is large. The lack of the supporting technology put forward a new challenge to the well logs.

3) Currently China lacks the core technologies of the well $\log$ s for the shale gas. As the shale reservoir have the characteristics of low productivity, less natural productivity and long-cycle production, the gas production depends on the horizontal well and the fracturing stimulation. The productivity evaluation is also difficult. Both experiences and the core technologies are all short, such as LWD/MWD and fracturing stimulation monitoring. 
4) Recently the well logs in oil and gas reservoir has been applied in shale gas reservoir and obtained some application effects. But the shale gas logs cannot satisfy with its the needs, such as lithology identification and geology evaluation, quantitative method for shale content, fracture and in-situ stress evaluation, LWD/MWD monitoring for horizontal well, microseismic monitoring for fracturing stimulation, etc.

\section{THE FUTURE RESEARCH FOCUS}

1) Quantitative identification method and model. As the lithology and hydrocarbon accumulation is uniqueness, the currently well log interpretation methods can't satisfy the production requirement. The novel logs interpretation methods and models in connection with shale reservoir should be built.

2) The quantitative evaluation models for the special logging suite. ECS and Imaging logs is also important for shale gas. The fracture identification, pore configuration, rock mechanics parameters and minerals composition obtained with the special logs should be investigated.

3) Real-time monitoring technology and well logs interpretation for the horizontal well. The horizontal well is also important for shale gas development. The monitoring and logging interpretation of the horizontal well is a direction attention, especially LWD/MWD application study.

4) Fracturing stimulation monitoring with well logs. The fracturing stimulation must be conducted for shale gas production as shale reservoir is tight and low productivity. The real-time monitoring of the fracturing operation is used to evaluate the fracture length and orientation. Currently microseismic monitoring in borehole is a developing direction.

\section{CONFLICT OF INTEREST}

The authors confirm that this article content has no conflict of interest.

\section{ACKNOWLEDGEMENTS}

We would appreciate Mingde Wu, Hong Yang and Guiqing Zhu for theirs useful suggestions. We are grateful to two reviewers for critical review and constructive comments of the manuscript. We also thank authors whose publications haven't listed in the references. The work is jointly supported by the National Key Basic Research Program of China (973 Program, No. 2014CB239201), National Natural Science Foundation of China (NSFC, No. 41374144) and Science Foundation of China University of Petroleum, Beijing (No. KYJJ2012-05-14).

\section{REFERENCES}

[1] C. Boyer, J. Kieschnick, E.R. Lewis, and G. Waters, "Producing gas from its source", Oilfield Review, vol. 18, pp. 36-49, 2006.

[2] K. Katahara, "What is shale to a petrophysicist?", The Leading Edge, vol. 27, pp. 738-741, 2008.

[3] D.J. Ross, R.M. Bustin, "The importance of shale composition and pore structure upon gas storage potential of shale gas reservoir", Marine and Petroleum Geology, vol. 26, pp. 916-927, 2009.
[4] C.H. Sondergeld, K.E. Newsham, J.T. Comisky, M.C. Rice, and C.S. Rai, "Petrophyscial considerations in evaluating and producing shale gas resources", In: Society of Petroleum Engineer Unconventional Gas Conference, SPE 131768, 2010.

[5] Y. Wei, W. Jinbo, L. Shuai, W. Kun, and Z. Yinan, "Logging identification for the Longmaxi mud shale reservoir on the Jiaoshiba area, Sichuan Basin", Natural Gas Industry (in Chinese), vol. 34, no. 6, pp. 30-36, 2014.

[6] Z. Xiaoling, Xiaolizhi, X. Ranhong, W. Heng, and G. Yang, "Petrophysical workflow for shale gas evaluation", Progress in Geophysics (in Chinese), vol. 28, pp. 1962-1974, 2013.

[7] J. Yuqiang, D. Dazong, and Q. Lin, "Basic features and evaluation of shale gas reservoirs", Natural Gas Industry (in Chinese), vol. 30, pp. 7-12, 2010.

[8] J. Gelb, A. Gu, T. Fong, L. Hunter, S.H. Lau, and W. Yun, "A closer look at shale : representative elementary volume analysis with laboratory 3D x-ray computed microtomography and nanotomography", In: Society of Core Analysis Annual Meeting, SCA-58, 2011.

[9] L. Qicui, L. Yisan, S. Wenzhuan, Y. Peng, S. Change, and G. Hao, "Application of FMI imaging logging in shale gas formation of Sichuan basin", Petroleum Geology and Engineering (in Chinese), vol. 27, no. 6, pp. 58-61, 2013.

[10] M. Xiuwen, L. Zhoubo, and P. Baozhi, "Method and advance of shale gas formation evaluation by means of well logging", Geological Bulletin of China (in China), vol. 30, pp. 400-405, 2011.

[11] L. Shuanglian, and L. Huangsheng, "Evaluation methods and characteristics of log evaluation technology in shale gas", Well Logging Technology (in Chinese), vol. 35, pp. 112-116, 2011.

[12] L. Rong, and L. Qing, "Log evaluation, seismic prediction and monitoring techniques of shale gas reservoirs", Natural Gas Industry (in Chinese), vol. 31, pp. 34-39, 2011.

[13] Z. Weidong, G. Min, and J. Zaixing, "Parameters and method for shale gas reservoir evaluation", Natural Gas Geoscience (in Chinese), vol. 22, pp. 1093-1099, 2011.

[14] Q. Baoquan, Y. Xiaobing, Z. Shudong, and C. Zhen, "Shale gas reservoirs evaluation with logging data in the south of Sichuan Basin”, Natural Gas Industry (in Chinese), vol. 31, pp. 44-47, 2011.

[15] P. Marouby, Z. Heidari, and T.C. Verdin, "Assessment of in-situ elastic properties of hydrocarbon-bearing shale with the joint quantitative interpretation of sonic, nuclear, and resistivity logs", In: SPWLA 52 $2^{\text {nd }}$ Annual Logging Symposium, Paper O, 2011.

[16] D. Buller, S. Kwong, D. Spain, and M. Miller, "A novel approach to shale-gas evaluation using a cased-hole pulsed neutron tool", In: SPWLA $51^{\text {st }}$ Annual Logging Symposium, Paper IIII, 2010.

[17] P. Boonen, L. Zhipeng, X. Libai, and W. Schultz, "Application of triple neutron porosity measurement in gas shales and shaly sands", In: SPWLA 51 $1^{\text {st }}$ Annual Logging Symposium, Paper JJJ, 2010.

[18] R.W. Spears, D. Dudus, A. Foulds, Q. Passey, S. Sinha, and W.L. Esch, "Shale gas core analysis: strategies for normalizing between laboratory and a clear need for standard materials", In: SPWLA $52^{\text {nd }}$ Annual Logging Symposium, Paper A, 2011.

[19] C. Stamm, H. Homann, S. Creden, C.H. Freitag, C. Fulda and G. Lindsay, "Barnett shales - new LWD sensor technology provides crucial formation evaluation information at reduced cost and risk for land operations", In: SPWLA 48 $8^{\text {th }}$ Annual Logging Symposium, Paper OO, 2007.

[20] I. Brevik, G.R. Ahmadi, T. Hatteland, and M.A. Rojas, "Documentation and quantification of velocity anisotropy in shales using wireline log measurements", The Leading Edge, vol. 26, pp. 272277, 2007.

[21] C. Skelt, "Petrophysical analysis of the Green river formation, southwestern Colorado - A case study in oil shale formation evaluation", In: SPWLA 51 ${ }^{s t}$ Annual Logging Symposium, Paper EEEE, 2010 .

[22] R.L. Eastwood, and U. Hammes, "Log model development for the Bossier and Haynesville shales", In: SPWLA $52^{\text {nd }}$ Annual Logging Symposium, Paper L, 2011.

[23] A. Donald, A. Ritchie, D. Goodwin, V. Garnier, A. Syed, and F.B. Parra, "Real-time and time-lapsed LWD density images for managing wellbore stability of weak overburden shale: case study for the Bream field, offshore Norway", In: SPWLA $52^{\text {nd }}$ Annual Logging Symposium, Paper V, 2011.

[24] X. Bo, L. Jinghan, and L. Xiaoge, "Evaluation of hydrocarbon accumulation conditions for shale gas from the eastern sag of the 
Liaohe oilfield and its gas-bearing properties", ACTA Petrolei Sinica (in Chinese), vol. 32, pp. 450-458, 2011.

[25] P. Renfang, W. Yuan, and S. Zheng, "Geochemical parameters used for shale gas exploration and basic methods for well logging analysis", China Petroleum Exploration (in Chinese), vol. 13, pp. 6-9, 2009.

[26] D.C. Heddleston, and M. Haggarty, "Shale gas horizontal production logging measurements and changes", In: Society of Petroleum Engineer Annual Meeting, SPE133134, 2010.

[27] R. Rickman, M. Mullen, E. Petre, B. Grieser, and D. Kundert, “A practical use of shale petrophysics for stimulation design optimization: all shale plays are not clones of the Barnett shale", In: Society of Petroleum Engineer Annual Meeting, SPE 115258, 2009.

[28] K.A. Bowker, "Barnett shale gas production, Fort Worth Basin: Issues and discussion", AAPG Bulletin, vol. 91, pp. 523-533, 2007.

[29] C. Chadwick, and C. Whittaker, "Production logging challenges in horizontal shale gas wells", In: SPWLA $52^{\text {nd }}$ Annual Logging Symposium, Paper $\mathrm{H}, 2011$.

[30] C.A. Andre, A.M. Cunha, P. Boonen, B.V. Spaight, S. Lefors, and W. Schultz, "A comparison of logging-while-drilling and wireline nuclear porosity logs in shales from wells in Brazil", In: SPWLA $45^{\text {th }}$ Annual Logging Symposium, Paper D, 2004.

[31] Y. Zhu, E. Liu, A. Martinez, M.A. Payne, and C.E. Harris, "Understanding geophysical responses of shale-gas plays", The Leading Edge, vol. 30, pp. 332-338, 2011.

[32] J. Nieto, R. Bercha, and J. Chan, "Shale gas petrophysics - Montney and Muskwa, are they Barnett look - alikes?", In: SPWLA 50 Annual Logging Symposium, Paper CCC, 2009.

[33] Z. Heidari, and T. Verdin, "Quantitative method for estimating total organic carbon and porosity, and for diagnosing mineral constituents from well logs in shale - gas formations", In: SPWLA $52^{\text {nd }}$ Annual Logging Symposium, Paper Q, 2011.

[34] J. Hemingway, and E. Rylander, "Formation evaluation in cased hole horizontal shale gas wells using inelastic and capture spectroscopy", In: SPWLA 52 ${ }^{\text {nd }}$ Annual Logging Symposium, Paper ZZ, 2011.

[35] L. Jun, L. Jing, L. Zheng, W. Qingzhao, and N. Zeyu, "Four pore modeling and its quantitative logging description of shale gas reservoir", Oil \& Gas Geology (in Chinese), vol. 35, pp. 266-271, 2014.

[36] L. Yanjun, Z. Liehui, F. Yuanyuan, L. Huan, L. Di, L. Jiaxia, and Jia Xuecheng, "Logging evaluation method and its application for measuring the total organic content in shale gas", Natural Gas Geoscience (in Chinese), vol. 24, pp. 169-175, 2013.

[37] X. Qingming, C. Lijun, L. Junfeng, H. Zhenhua, L. Hongying, W. Fei, and Z. Yingying, "Well logging interpretation and evaluation of gas shale reservoir at Longmaxi cormation in Qianjing area Southeast of Chongqing area", Progress in Geophysics (in Chinese), vol. 29, pp. 1312-1318, 2014.

[38] Q.R. Passey, S. Creaney, J.B. Kulla, F.J. Moretti, and J.D. Stroud, "A practical model for organic richness from porosity and resistivity logs", AAPG Bulletin, vol. 74, pp. 1777-1794, 1990.

[39] Q.R. Passey, K.M. Bohacs, W.L. Esch, R.K. Klimentidis, and S. Sinha, "From oil-prone source rock to gas-producing shale reservoir-geologic and petrophysical characterization of unconventional shale-gas reservoirs", In: CPS/SPE International Oil \& Gas Conference and Exhibition in China, SPE 131350, 2010.

[40] H. Zhao, B. Natalie, and B. Curtis, "Thermal maturity of the Barnett shale determined from well-log analysis", AAPG Bulletin, vol. 91, pp. 535-549, 2007.

[41] B. Anderson, T.D. Barber, M. Luling, and P. Sen, "Observations of large dielectric effects on induction logs, or, can source rocks be detected with induction measurement?", In: SPWLA 4 $7^{\text {th }}$ Annual Logging Symposium, Paper OOO, 2006.
[42] B. Anderson, T. Barber, M. Luling, P. Sen, R. Taherian, and J. Klein, "Identifying potential gas-producing shales from large dielectric permittivities measured by induction quadrature signals", In: SPWLA 49 ${ }^{\text {th }}$ Annual Logging Symposium, Paper HHHH, 2008.

[43] N.V. Seleznev, R.L. Kleinberg, and M.M. Herron, "Application of dielectric dispersion logging to oil - shale reservoirs", In: SPWLA $52^{\text {nd }}$ Annual Logging Symposium, Paper G, 2011.

[44] V. Shabro, T.C. Verdin, and F. Javadpour, "Pore-scale quantification of apparent permeability and electrical resistivity of hydrocarbon-bearing shale in the presence of gas desorption", In: SPWLA $52^{\text {nd }}$ Annual Logging Symposium, Paper K, 2011.

[45] D.L. Luffel, and F.K. Guidry, "New core analysis methods for measuring reservoir rock properties of Devonian Shale", Journal of Petroleum Technology, SPE 20571, pp. 1184-1190, 1992.

[46] D.L. Luffel, C.W. Hopkins, and P.D. Schettler, "Matrix permeability measurement of gas productive shales", In: Society of Petroleum Engineer Unconventional Gas Conference, SPE 26633, 1992.

[47] S. Zhang, R.E. Klimentidis, and P. Barthelemy, "Porosity and permeability analysis on nanoscale FIB-SEM 3D imaging of shale rock", In: Society of Core Analysis Annual Meeting, SCA-30, 2011

[48] R.G. Loucks, R.M. Reed, S.C. Ruppel, and D.M. Jarvie, "Morphology, genesis, and distribution of nanometer- scale pores in siliceous mudstone of Mississippian Barnet shale", Journal of Sedimentary Research, vol. 79, pp. 848-861, 2009.

[49] C.R. Clarkson, N. Solano, and R.M. Bustin, "Pore structure characterization of North America shale gas reservoir using USANS/SANS, gas adsorption, and mercury intrusion", Fuel, vol. 103, pp. 606-616, 2013.

[50] J. Klaver, G. Desbois, R. Littke, and J.L. Urai, "BIB-SEM characterization of pore space morphology and distribution in postmature to overmature samples from Haynesville and Bossier shales", Marine and Petroleum Geology, vol. 59, pp. 451-466, 2015.

[51] L. Vernik, and L. Xingzhou, "Velocity anisotropy in shales: A Petrophysical study", Geophysics, vol. 60, pp. 521-532, 1997.

[52] D. Patterson, N. Mekic, A. Bolshakov, B. Rajappa, and X.M. Tang, "Unconventional reservoir fracture evaluation utilizing deep shearwave imaging", In: SPWLA 52 ${ }^{\text {nd }}$ Annual Logging Symposium, Paper M, 2011.

[53] M. Pervukhinaa, D. Dewhurst, B. Gurevich, U. Kuila, T. Siggins, M. Raven, and H.M. Bolas, "Stress-dependent elastic properties of shales: Measurement and modeling", The Leading Edge, vol. 27, pp. 772-779, 2008.

[54] O.S. Audrey, S. Joel, and G. Yves, "A simplified model of effective elasticity for anisotropy shales", Geophysics, vol. 74, pp. D57D63, 2009.

[55] J.A. Ortega, F.J. Ulm, and Y. Abousleiman, "The nanogranular acoustic signature of shale", Geophysics, vol. 74, pp. D65-D84, 2009.

[56] C.H. Sondergeld, and C.S. Rai, "Elastic anisotropy of shales", The Leading Edge, vol. 30, pp. 324-331, 2011.

[57] D.N. Dewhurst, A.F. Siggins, J. Sarout, M.D. Raven, and H.M. Bolas, "Geomechanical and ultrasonic characterization of Norwegian Sea shale", Geophysics, vol. 76, pp. WA101-WA111, 2011.

[58] R.M. Slatt, and Y. Abousleiman, "Merging sequence stratigraphy and geomechanics for unconventional gas shales", The Leading Edge, vol. 30, pp. 274-282, 2011.

[59] L. Vernik, and J. Milovac, "Rock physics of organic shales", The Leading Edge, vol. 30, no. 3, pp. 318-323, 2011.

[60] Y. Junliang, D. Jingen, Z. Dingyu, L. Dahua, Y. Wei, C. Chaogang, C. Lijun, and C. Zijian, "Fracability evaluation of shale-gas reservoirs", Acta Petrolei Sinica (in Chinese), vol. 34, pp. 523-527, 2013.

(C) Zhang et al.; Licensee Bentham Open.

This is an open access article licensed under the terms of the Creative Commons Attribution Non-Commercial License (http://creativecommons.org/licenses/by-nc/3.0/) which permits unrestricted, non-commercial use, distribution and reproduction in any medium, provided the work is properly cited. 